\title{
Psychological and Physical Workload and the Development of Musculoskeletal Symptoms Among Female Elderly-Care Workers
}

\author{
Pernilla Larsman and Jan Johansson Hanse*
}

\author{
Department of Psychology, University of Gothenburg, Göteborg, Sweden
}

\begin{abstract}
The aim of the present study was to investigate the relations between psychological and physical workload and musculoskeletal neck, shoulder and upper back symptoms. In this longitudinal two-phase cohort study a survey was conducted among non-managerial female elderly-care workers $(n=553)$. The analyses were based on respondents who were considered free from the respective symptoms at initial ratings, resulting in study samples of $n=230$ for neck symptoms, $n=211$ for shoulder symptoms, $n=400$ for upper back symptoms, and $n=204$ for low back symptoms. The results indicate that psychological workload is related to the development of musculoskeletal (neck and upper back) symptoms measured at an 18-month follow-up, both in itself and in combination with physical workload. The most important finding was that psychological workload shows significant temporal relations to neck and upper back symptoms.
\end{abstract}

Keywords: Psychological workload, physical workload, musculoskeletal symptoms, elderly-care workers.

\section{INTRODUCTION}

Musculoskeletal symptoms are a common problem among health-care workers (elderly-care workers, homecare workers and nurses) [1-7]. It has been suggested that stress related to demanding physical and psychosocial working conditions contributes to the development and maintenance of musculoskeletal symptoms within this occupational group [3]. In general, this kind of work has been shown to be characterized by long periods of standing and walking and frequent occurrence of postures potentially harmful for the low back and shoulders [8], and high time pressure and high conflicting demands have been reported in this occupation [9]. Physical work-related risk factors for neck/shoulder and back symptoms among these workers include standing in forward-bent, twisted and awkward postures and lifting heavy loads $[2,4,6,10]$, as well as patient handling tasks involving reaching, pushing and pulling with outstretched arms/shoulders [11]. A high psychological workload, high quantitative demands, time pressure, low job control and job dissatisfaction are among the suggested psychosocial risk factors for neck, shoulder and back pain and pain-related disability [12-14].

Warren [15] argues that the link between psychosocial and physical stressors makes it difficult to estimate their associations with ill health separately. Multivariable methods containing both psychosocial and physical stressors as well as their interaction terms are recommended [16]. Previous studies indicate that a combination of adverse psychosocial work factors (e.g. a high psychological workload, low social support, low decision latitude) and a high physical workload is associated with an increased risk of suffering from neck/shoulder and back symptoms among elderly-care workers $[2,6,13]$. However it is important that these associations

\footnotetext{
*Address correspondence to this author at the Department of Psychology, University of Gothenburg, Göteborg, Sweden; Tel: +46 (0)31 786 1652; E-mail: jan.johansson.hanse@psy.gu.se
}

are investigated in longitudinal studies. The aim of the present study was therefore to investigate psychological and physical workload, as well as their interaction, as potential risk factors for the development of neck, shoulder, upper back and low back musculoskeletal symptoms in a twophase longitudinal study with an 18- month interval between phases.

\section{MATERIALS AND METHODS}

\section{Design and Procedure}

The present study is part of a longitudinal cohort study with survey data collected in the $1990 \mathrm{~s}$, with an 18 months distance between the two phases. Ethical approval was obtained by the Swedish Data Inspection Board, and informed consent was provided. The study is based on a survey among employees in Swedish human service organizations [17]. The response rate at phase 1 was approximately $80 \%$ and about $78 \%$ of the respondents participated in both phases. Telephone interviews were conducted on a subsample (about $40 \%$ ) of the participants who participated in phase I but not in phase 2. Among the most common reasons for not responding to the follow-up questionnaire were maternity leave, age-related retirement and absence due to studies.

\section{Participants}

The sample consisted of non-managerial female elderlycare workers $(n=553)$. The most common types of elderlycare setting were homecare work $(41 \%)$, i.e., work in the patients' own home, and work in different types of nursing homes $(53 \%)$. At the initial ratings 160 respondents $(29 \%)$ were between 20 and 34 years old, $250(45 \%)$ were between 35 and 49 years old and $142(26 \%)$ were between 50 and 64 years old. The seniority of the participants was rather high, with $69 \%$ having more than 5 years of employment, and only $10 \%$ having less than one year of employment. Prevalence of symptoms during the past 12 months at the initial ratings was $58 \%$ for the neck, $62 \%$ for the shoulders, $27 \%$ for the upper back, and $63 \%$ for the low back. Because the aim of the 
study was to investigate risk factors for the development of symptoms, the analyses for the different body regions were based on respondents who were considered free from the respective symptoms at the initial ratings, i.e., those participants reporting no symptoms during the past 12 months, resulting in study samples of $n=230$ for neck symptoms, $n=$ 211 for shoulder symptoms, $n=400$ for upper back symptoms, and $n=204$ for low back symptoms. See Table 1 for a description of symptom prevalence at phase 1 and symptom prevalence (among those initially symptom-free) at phase 2 .

Table 1. Symptom Prevalence During the Past 12 Months at Phase 1 and 2

\begin{tabular}{|c|c|c|}
\hline & Phase 1 Prevalence & Phase 2 Prevalence* \\
\hline \hline Neck symptoms & $58 \%(n=553)$ & $33 \%(n=230)$ \\
\hline Shoulder symptoms & $62 \%(n=553)$ & $34 \%(n=211)$ \\
\hline Upper back symptoms & $27 \%(n=553)$ & $19 \%(n=400)$ \\
\hline Low back symptoms & $63 \%(n=553)$ & $35 \%(n=204)$ \\
\hline
\end{tabular}
1 .

Neither seniority nor type of elderly-care setting were associated with symptom prevalence at phase 1 , while age was associated with prevalence of upper back symptoms (but not other symptoms) such that workers aged 20-34 years had experienced upper back symptoms to a higher extent than had workers aged 35-49 years or 50-64 years $\left(\chi^{2}=8.68, \mathrm{df}=\right.$ $2, \mathrm{p}<.05$ ). Symptom prevalence at phase 2 (among those participants considered symptoms-free at phase 1) was not associated with seniority, age or type of elderly-care setting (data not shown).

\section{Measures}

Employee perceptions of their appraised (self-reported) Psychological workload were measured using a short version [17] of the PAK questionnaire [18,19], consisting of the items "time pressure at work", "work overload", and "mental pressure" (Cronbach's $\alpha=.69$ ), where each item has five fixed response alternatives ranging from very unsatisfactory to very satisfactory. Appraised psychological workload was constructed by deriving the mean value for these items, with high mean values indicating a high psychological load.

Physical workload was assessed using seven questionnaire items about self-assessed work postures [20-22], an additional question concerning repetitive work movements [23], and six questionnaire items about lifting (heavy) loads (frequency and duration) (Cronbach's $\alpha=.82$ ). Questionnaire items regarding physical workload are reported in Table 2. Each of these questionnaire items (except items relating to the frequency of heavy lifting) originally had six fixed response alternatives ranging from "not at all" to "almost all the time", however as has been recommended [24] these six response alternatives were collapsed into three categories; "not at all" and "about $1 / 10$ of the time" into low exposure, "about $1 / 4$ of the time" and "about $1 / 2$ of the time" into medium exposure, and "about $3 / 4$ of the time" and "almost all the time" into high exposure. Items relating to the frequency of heavy lifting had five fixed response alternatives ranging from "not at all" to "more than 30 times per hour". The vari- able physical workload was constructed by deriving the mean value for these items, with high mean values indicating a high physical load.

Musculoskeletal symptoms were assessed using the general Nordic Musculoskeletal Questionnaire (NMQ) [25]. The present study deals with symptoms (yes/no) in the Neck, Shoulder, Upper back and Low back during the past 12 months.

Table 2. Questionnaire Items Assessing Physical Workload

\begin{tabular}{|c||l|}
\hline \multicolumn{1}{|l||}{ Work postures } & $\begin{array}{l}\text { trunk bent forward } 20-60^{\circ} \\
\text { trunk bent forward }>60^{\circ}\end{array}$ \\
& $\begin{array}{l}\text { trunk rotation }>45^{\circ} \\
\text { hands above shoulder level } \\
\text { head bent forward } \\
\text { head bent backward } \\
\text { head heavily rotated }\end{array}$ \\
\hline \multirow{2}{*}{ Repetitive work } & constant repetition of movements \\
\hline lifting or handling & $\begin{array}{l}\text { duration: lifting/handling } 1-5 \mathrm{~kg} \\
\text { duration: lifting } / \text { handling } 6-15 \mathrm{~kg} \\
\text { duration: lifting/handling }>15 \mathrm{~kg} \\
\text { frequency: lifting/handling } 1-5 \mathrm{~kg} \\
\text { frequency: lifting/handling } 6-15 \mathrm{~kg} \\
\text { frequency: lifting/handling }>15 \mathrm{~kg}\end{array}$ \\
\hline
\end{tabular}

\section{Statistical Analysis}

In order to compare the risk of developing symptoms among those exposed to high versus low psychological and physical workloads, these factors were dichotomized by using the median split for the respective variable. A composite variable combining exposure to psychological and physical load was also constructed so that differences in risks between subjects with different exposure patterns could be assessed. Odds Ratios (OR) including 95\% confidence intervals $(\mathrm{CI})$ were calculated using logistic regression with SPSS version 13 .

\section{RESULTS}

Of those elderly-care workers free from the respective symptom at initial ratings, $33 \%$ had developed neck symptoms, $34 \%$ had developed shoulder symptoms, $19 \%$ had developed upper back symptoms, and 35\% had developed low back symptoms at follow-up ratings. Odds Ratios including $95 \%$ confidence intervals for neck, shoulder and upper back symptoms are reported in Table $\mathbf{3}$.

Psychological workload at initial ratings was related to neck symptoms at follow-up, i.e., those workers exposed to a high psychological workload at initial ratings had a higher risk of having developed neck symptoms at follow-up ratings compared to those exposed to low levels of psychological workload $(\mathrm{OR}=2.11$, CI: $1.19,3.77)$. Psychological workload at initial ratings was similarly related to upper back symptoms $(\mathrm{OR}=2.97, \mathrm{CI}: 1.78,4.98)$, but was not related to shoulder or low back symptoms.

When assessing the combined effects of psychological and physical workload, workers exposed to a high psychological workload in combination with a high physical work- 
Table 3. Odds Ratios (OR) with $95 \%$ Confidence Intervals (CI) for Neck, Shoulder and Upper Back Symptoms Between Groups of Home Care Workers with "High" Compared to "Low" Risk-Indicator Scores. Significant ORs are Marked in Boldface

\begin{tabular}{|c|c|c|c|c|}
\hline Risk Indicator & $\begin{array}{l}\text { Neck OR } \\
(95 \% \text { CI })\end{array}$ & $\begin{array}{c}\text { Shoulder OR } \\
(95 \% \text { CI })\end{array}$ & $\begin{array}{c}\text { Upper Back OR } \\
(95 \% \text { CI })\end{array}$ & $\begin{array}{c}\text { Low Back OR } \\
(95 \% \text { CI })\end{array}$ \\
\hline Psychological workload (high/low) & $2.11(1.19,3.77)$ & $0.72(0.38,1.36)$ & $2.97(1.78,4.98)$ & $1.14(0.61,2.13)$ \\
\hline Physical workload (high/low) & $0.77(0.44,1.35)$ & $0.82(0.46,1.46)$ & $1.29(0.78,2.13)$ & $1.08(0.60,1.94)$ \\
\hline \multicolumn{5}{|c|}{ Combined Effects of Psychological and Physical Load* } \\
\hline Low psychological workload and high physical workload & $1.07(0.52,2.20)$ & $1.07(0.54,2.15)$ & $0.76(0.34,1.68)$ & $0.86(0.41,1.77)$ \\
\hline High psychological workload and low physical workload & $3.94(1.73,8.97)$ & $1.08(0.44,2.65)$ & $2.43(1.13,5.24)$ & $0.74(0.26,2.13)$ \\
\hline High psychological workload and high physical workload & $1.28(0.58,2.86)$ & $0.55(0.23,1.31)$ & $\mathbf{2 . 8 4}(1.51,5.32)$ & $1.26(0.58,2.73)$ \\
\hline
\end{tabular}

* The different exposure combinations are compared to the most beneficial work environment, i.e., a low psychological workload in combination with a low physical workload.

load were at a higher risk of developing upper back symptoms than workers in the lowest exposure group (low psychological in combination with low physical exposure) (OR $=2.84$, CI: $1.51,5.32$ ). No such effects were however detected for neck, shoulder or low back symptoms. A high psychological workload in combination with a low physical workload was also related to neck symptoms $(\mathrm{OR}=3.94$, CI: $1.73,8.97)$ and upper back symptoms (OR $=2.43, \mathrm{CI}: 1.13$, $5.24)$ but not to shoulder or low back symptoms. No bivariate relations of mechanical workload at the initial ratings on the development of symptoms (neck, shoulder, upper back or low back) were detected in the present analyses.

\section{DISCUSSION}

The prevalence of neck (58\%), shoulder (62\%) and low back $(63 \%)$ symptoms was high at initial ratings. This corresponds to findings of previous studies [6, 26-28], and further highlights the importance of addressing musculoskeletal symptoms in elderly-care work. The 18-month incidence of symptoms (i.e., the development of symptoms among those without symptoms at initial ratings) was also fairly high for these body regions (33\% for neck symptoms, $34 \%$ for shoulder symptoms, and $35 \%$ for low back symptoms).

Psychological workload refers to the employee assessments of the total psychological workload imposed upon them by the working environment, which may lead to feelings of work overload, mental pressure and of being under time pressure at work. We view psychological workload as resulting from the individual's perception of the psychosocial work environment in total, including such aspects as the perceived work demands, the perceived job control and possibilities for development at work, and the perceived social support and feedback provided by colleagues and superiors at work. Psychological workload is thus an appraisal of the psychosocial work situation [17], and has been found to be a particularly important risk indicator (in relation to other indices of the work environment; perceived job characteristics) for musculoskeletal symptoms in many studies [6, 29, 30]. Hedin [31], in a study among homecare workers, found results suggesting the subjective (appraised) workload to be a better predictor of diffuse musculoskeletal complaints than the subjective workload. In the present study a high psychological workload at initial ratings (being under time pressure at work, and experiencing work overload and mental pressure) was related to an increased risk of having developed neck $(\mathrm{OR}=2.11)$ and upper back $(\mathrm{OR}=2.97)$ symptoms, but not shoulder or low back symptoms. These results partly concur with the results found by Johansson [6] where a high psychological workload was associated with neck (OR = $1.52)$ and shoulder $(\mathrm{OR}=1.36)$ but not low back symptoms. In general, the finding that the psychological workload is related to neck and upper back symptoms but not low back symptoms corresponds to previous studies indicating that there may be different risk factors for neck/shoulder as compared to (low) back symptoms [2, 32-36].

A high psychological workload was also related to upper back symptoms $(\mathrm{OR}=2.84)$ when combined with a high mechanical load, and also when combined with a low mechanical load (neck, $\mathrm{OR}=3.94$ and upper back, $\mathrm{OR}=2.43$ ). These results are (partly) in accordance with those found by Johansson [6] where exposure to a poor psychosocial work environment (including a high psychological workload) in combination with a high mechanical load was related to work related neck and shoulder symptoms.

Physical workload (working with trunk bent forward or rotated, hands above shoulder level, head bent forward, backward or heavily rotated, lifting and handling heavy objects, and exposure to repetitive work movements) was not related to neck, shoulder, upper back or low back symptoms on its own. These results are contrary to those found in previous studies among home care workers, e.g. Johansson [6] where indicators of physical load (lifting heavy loads, twisted postures, forward flexed trunk, hands above shoulder level and monotonous work) was associated with neck, shoulder and low back symptoms (ORs ranging between 1.29 and 1.94) and Brulin et al. [2] where standing in bent forward, twisted and awkward postures was associated with neck/shoulder and low back symptoms. These results are also contrary to those of Luime et al. [37] who, in a longitudinal study among nursing home and elderly-care workers, found work in awkward postures to be related to the 1-year incidence of neck complaints. In a different occupational setting (forestry workers), Miranda et al. [38] found physically strenuous work and working with trunk forward flexed to be related to the 1-year incidence of shoulder pain. The results of our study partly concur with a study of a general occupational population in Denmark [39] where baseline twisting and bending work postures were found to be related to the 5-year incidence of neck/shoulder symptoms among men but not among women, and where no interaction effects between baseline physical (twisting and bending work postures and working with hands raised) and psychosocial (job 
demands, skill discretion, decision authority and social support) exposure were found.

The questionnaire items assessing physical workload were chosen based on previous research on physical risk factors for musculoskeletal symptoms. The absence of a relation between physical workload and musculoskeletal symptoms found in the previous study could however be interpreted as an indication of the questionnaire instrument lacking in precision, due to the omission of important occupation-specific physical stressors such as forceful exertion and specific patient handling tasks $[11,35]$. Since only workers symptom-free at initial ratings were included in the present analyses it is also possible that the physical load for these workers was not high enough to exceed the critical threshold where the loading becomes harmful, while those workers exposed to high levels of physical load during the previous years had already developed symptoms and were therefore excluded from the analyses. The omission of individual factors such as tolerances to physical workloads may further reduce the ability to detect an existing relation between physical workload and symptom development. An approach focusing on identifying physical and psychosocial risk factors specific to elderly-care work while controlling for individual factors is needed to further our understanding of the aetiology of musculoskeletal symptoms within this occupational group.

Little is known about the optimal time lags, i.e., the time frames necessary for psychosocial and physical stressors to have an impact on the development of musculoskeletal symptoms. In the present study a time lag of 18 months was employed, however, if this time lag is not optimal (i.e., it may be either too short or too long) the effects found in the present study may be under- or overestimates of the "true" effects (see Cole and Maxwell [40] for a discussion of time lags in longitudinal studies). Future research thus needs to focus on investigating and determining the optimal time lags within this research area.

\section{CONCLUSIONS}

The present study found appraised psychological workload to be related to musculoskeletal neck and upper back symptoms among female elderly-care workers. These results can be viewed in accordance with general theoretical models of work and health, e.g. the psychosocial stress model [41] where psychosocial stressors influence health through cognitive appraisals of the work situation. A high psychological workload increased the risk of developing neck and upper back symptoms, and the level of physical load only marginally affected this relation. The most important finding was that psychological workload showed significant temporal relations to neck and upper back symptoms. This could be a basis for appropriate psychosocial interventions.

\section{REFERENCES}

[1] Ando S, Ono Y, Shimaoka M, et al. Associations of self estimated workloads with musculoskeletal symptoms among hospital nurses. Occup Environ Med 2000; 57: 211-6.

[2] Brulin C, Gerdle B, Granlund B, Höög J, Knutson A, Sundelin G. Physical and psychosocial work-related risk factors associated with musculoskeletal symptoms among home care personnel. Scand J Caring Sci 1998; 12: 104-10.
[3] Brulin C, Winkvist A, Langendoen SL. Stress from working conditions among home care personnel with musculoskeletal symptoms. J Adv Nurs 2000; 31: 181-9.

[4] Byrns G, Reeder G, Jin G, Pachis K. Risk factors for work-related low back pain in registered nurses, and potential obstacles in using mechanical lifting devices. J Occup Environ Hyg 2004; 1: 11-21.

[5] Dellve L, Allebeck P, Hagberg M, Herloff B, Karlberg C, Lagerstöm M. Macro-socioeconomic determinants of occupational injuries and diseases among the total workforce of home care workers in Sweden. Safety Sci Monitor 2003; 7: 1-11.

[6] Johansson JÅ. Psychosocial work factors, physical workload and associated musculoskeletal symptoms among home care workers. Scand J Psychol 1995; 36: 113-29.

[7] Karahan A, Bayraktar N. Determination of the usage of body mechanics in clinical settings and the occurrence of low back pain in nurses. Int J Nurs Stud 2004; 41: 67-75.

[8] Torgén M, Nygård C, Kihlbom Å. Physical work load, physical capacity and strain among elderly female aides in home-care service. Eur J Appl Physiol 1995; 71: 444-52.

[9] Josefsson K, Sonde L, Winblad B, Robins Wahlin TB. Work situation of registered nurses in municipal elderly care in Sweden: A questionnaire survey. Int J Nurs Stud 2007; 44: 71-82.

[10] Ono Y, Lagerström M, Hagberg M, Lindén A, Malker B. Reports of work related musculoskeletal injury among home care service workers compared with nursery school workers and the general population of employed women in Sweden. Occup Environ Med 1995; 52: 686-93.

[11] Smedley J, Inskip H, Trevelyan F, Buckle P, Cooper C, Coggon D. Risk factors for incident neck and shoulder pain in hospital nurses. Occup Environ Med 2002; 60: 864-9.

[12] Gunnarsdottir HK, Rafnsdottir GL, Helgadottir B, Tomasson K. Psychosocial risk factors for musculoskeletal symptoms among women working in geriatric care. Am J Ind Med 2003; 44: 679-84.

[13] Johansson JÅ. The impact of decision latitude, psychological load and social support at work on musculoskeletal symptoms. Eur J Public Health 1995; 5: 169-74.

[14] Simon M, Tackenberg P, Nienhaus A, Estryn-Behar M, Conway PM, Hasselhorn PM. Back or neck-pain-related disability of nursing staff in hospitals, nursing home and home care in seven countries - results from the European NEXT-Study. Int J Nurs Stud 2008; 45: 24-34

[15] Warren N. Psychosocial and work organization risk factors for work-related musculoskeletal disorders. Karwowski W, Ed. International Encyclopedia of Ergonomics and Human Factors. London: Taylor \& Francis 2001.

[16] Punnett L. Work related neck pain: How important is it, and how should we understand its causes? Occup Environ Med 2004; 61: 954-5.

[17] Pousette A, Johansson Hanse J. Job characteristics as predictors of ill-health and sickness absenteeism in different occupational types - a multigroup structural equation modeling approach. Work Stress 2002; 16: $229-50$

[18] Rubenowitz S. Management and job organization in progressive Swedish industries. Göteborg: University of Gothenburg; 1989. Reports from the Department of Applied Psychology. Report no 12.

[19] Rubenowitz S. Survey and intervention of ergonomic problems at the workplace. Int J Ind Ergon 1997; 19: 271-5.

[20] Wiktorin C, Karlqvist L, Nygård CH, Winkel J. Design and reliability of a questionnaire for estimation of physical load in epidemiologic studies. Quéinnec Y, Daniellou F, Eds. Designing for Everyone. Proceedings of the Eleventh Congress of the International Ergonomics Association. London: Taylor \& Francis 1991.

[21] Wiktorin C, Karlqvist L, Winkel J. Validity of self-reported exposures to work postures and manual materials handling. Scand J Work Environ Health 1993; 19: 208-14.

[22] Winkel J, Dallner M, Ericson M, et al. Evaluation of a questionnaire for the estimation of physical load in epidemiologic studies. Hagberg M, Kilbom Å, Eds. International Scientific Conference on Prevention of Work-related Musculoskeletal Disorders. Arbete och Hälsa 1992:17.

[23] Johansson JÅ, Rubenowitz S. Risk indicators in the psychosocial and physical work environment for work-related neck, shoulder and low back symptoms: a study among blue- and white-collar workers in eight companies. Scand J Rehabil Med 1994; 26: 13142 . 
[24] Balogh I, Ørbaek P, Winkel J, et al. Questionnaire-based mechanical exposure indices for large population studies - reliability, internal consistency and predictive validity. Scand J Work Environ Health 2001; 27: 41-8.

[25] Kuorinka I, Jonsson B, Kilbom Å, et al. Standardised Nordic questionnaires for the analysis of musculoskeletal symptoms. Appl Ergon 1987; 18: 233-7.

[26] Elert J, Brulin C, Gerdle B, Johansson H. Mechanical performance, level of continuous contraction and muscle pain symptoms in home care personnel. Scand J Rehabil Med 1992; 24: 141-50.

[27] Malker HSR, Hedlin M, Malker BK, Weiner JA. Yrkesrelaterade belastningsskador. Risk-identifiering med hjälp av ISA (Workrelated musculoskeletal injuries by occupation. Risk identification using ISA). Stockholm: Arbetsmiljöinstitutet; 1990. Arbete och Hälsa 1990:29. (in Swedish, English summary).

[28] Tuomi K, Ilmarinen J, Eskelinen L, Järvinen E, Toikkanen J, Klockars M. Prevalence and incidence rates of diseases and work ability in different work categories of municipal occupations. Scand J Work Environ Health 1991; 17: 67-74.

[29] Engström T, Johansson Hanse J, Kadefors R. Musculoskeletal symptoms due to technical preconditions in long cycle time work in an automobile assembly plant: a study of prevalence and relation to psychosocial factors and physical exposure. Appl Ergon 1999; 30: 443-53.

[30] Ohlsson K, Hansson GÅ, Balogh I, et al. Disorders of the neck and upper limbs in women in the fish processing industry. Occup Environ Med 1994; 51: 826-32.

[31] Hedin AM. From different starting points - A longitudinal study of work and health among home care workers. Eur J Public Health 1997; $7: 272-8$

[32] Ariens G, van Mechelen W, Bongers P, Bouter L, van der Wahl G. Psychosocial risk factors for neck pain: a systematic review. Am J Ind Med 2001; 39: 180-93.
[33] Bru E, Mykletun RJ, Svebak S. Work-related stress and musculoskeletal pain among female hospital staff. Work Stress 1996; 10: 301-21.

[34] Hoogendoorn WE, van Poppel MNM, Bongers PM, Koes BW, Bouter LM. Systematic review of psychosocial factors at work and private life as risk factors for back pain. Spine 2000; 25: 2114-25.

[35] NIOSH. Musculoskeletal disorders and workplace factors. A critical review of epidemiologic evidence for work-related musculoskeletal disorders of the neck, upper extremity, and low back. (NIOSH Publication No. 97-141). U.S. Department of Health and Human Services. Public Health Service. Centers for Disease Control and Prevention. Cincinnati, USA: National Institute for Occupational Safety and Health, 1997.

[36] Van der Windt D, Thomas E, Pope D, et al. Occupational risk factors for shoulder pain: A systematic review. Occup Environ Med 2000; 57: 433-42.

[37] Luime JJ, Kuiper JI, Koes BW, Verhaar JAN, Miedema HS, Burdorf A. Work-related risk factors for the incidence and recurrence of shoulder and neck complaints among nursing-home and elderlycare workers. Scand J Work Environ Health 2004; 30: 279-86.

[38] Miranda H, Viikari-Juntura E, Martikainen R, Takala EP, Riihimäki H. A prospective study of work related factors and physical exercise as predictors of shoulder pain. Occup Environ Med 2001; 58: $528-34$

[39] Feveile H, Jensen C, Burr H. Risk factors for neck-shoulder and wrist-hand symptoms in a 5-year follow-up study of 3,990 employees in Denmark. Int Arch Occup Environ Health 2002; 75: 243-51.

[40] Cole DA, Maxwell SE. Testing mediational models with longitudinal data: Questions and tips in the use of structural equation modeling. J Abnorm Psychol 2003; 112: 558-77.

[41] Sauter SL, Swanson NG. An ecological model of musculoskeletal disorders in office work. Moon SD, Sauter SL, Eds. Beyond biomechanics. Psychosocial aspects of musculoskeletal disorder in office work. London: Taylor \& Francis 1996.

(C) Larsman and Hanse; Licensee Bentham Open.

This is an open access article distributed under the terms of the Creative Commons Attribution License (http://creativecommons.org/licenses/by/2.5/), which permits unrestrictive use, distribution, and reproduction in any medium, provided the original work is properly cited. 